phases of life, and in the present work the matter is put forth with an unusually frank and direct presentation and thoughtfulness of practical issues.

Forel begins with a general biological sketch, including the excrescences of the sexual instinct, the development of marital forms, etc.; he then reviews the sexual pathology, and discusses the rôle of suggestion in sexual life, the financial economic side of the sexual question, the influence of the environment, the relation of the problem to religion, to law, to medicine, to ethics, politics and economics, pedagogy and art, and finally a sketch of perspectives of the future. In an appendix Forel reviews some prominent works by other writers, such as August Bebel's 'Die Frau,' Ellen Key's 'Ueber Liebe und Ehe,' Guy de Maupassant's novels, Couvreur's 'La Graine, etc.

Throughout, the book is a model of concreteness; and in the numerous dilemmas with which the practical psychologist and physician are confronted a long experience and sound instincts, not merely of reserve but of action, make Forel's work the source of much help and many suggestions.

Any one who wishes to get an idea of the sociological idealism pervading the work of the great champion of racial progress, will do well to read a pamphlet entitled 'Sexuelle Ethik,' published by Ernst Rheinhardt, Muenich, 1906. To this program Forel adds some instances of ethical sexual conflicts from life, illustrating the complex nature of the topic and the need of the expression of the experience of the best of our race, instead of mere confidence in conventionalism and fatalism.

\title{
RESTORATION OF FUNCTION.
}

Ueber den Wiederersatz der Funktion bei Erkrankungen des

Gehirnes. G. Axton. Berlin, S. Karger, Igo6.

Anton has chosen for his opening lecture as successor of Wernicke, at Halle, a topic which is well worth a brief review. Clinical and experimental work has of late years attempted to analyze the important phenomena of substitution of function in lesions of the nervous system. Many lesions of the frontal and parietal lobe, cerebellar defects and one-sided destruction of the striatum may be devoid of any symptoms and are especially apt to be smoothed over in childhood. But even in a gentleman of seventy, Anton found numerous small foci of arteriosclerotic softening in the brain without any deterioration of his acute intellect and judgment and social adaptation and self-regulation. In view of the scantiness or practical absence of regenerative processes in 
the central nervous system, the studies on substitution or adaptation of function by Ewald and Bickel have proved to be of great interest. The disorders of attitude and balance following destruction of one labyrinth in a dog is readily recovered from; even the profounder effects of destruction of the second labyrinth are corrected again, after a few months ; removal of one motor area caused a crossed hemiplegia plus relapse of the typical disorders of coördination of the hemiplegic side, but even these were corrected again for running and jumping, even in the dark. Removal of the other motor area caused an irreparable loss not only of the double hemiplegic type with inability to do tricks, but a relapse of the labyrinth symptoms. What little restitution of coördination occurred was at the mercy of the use of the eyes and failed when they were closed. Passing over the well-known substitutions of cerebellar functions, we refer to Bickel's experiment: section of the posterior roots of both hind-legs, compensation of the ensuing spinal ataxia; then removal of both sensory-motor regions of the cortex, with complete relapse of the spinal ataxia for the hind-legs and appearance of simple cerebral ataxia in the forelegs. Many experimental and clinical data and the substitution of aphasic defects furnish excellent instances in a higher sphere, and the same undoubtedly holds for the highest functions. The new adjustments have, however, some residual marks : greater fatigability of the new mechanisms, defect under special demands, such as movements of the legs in suspension, during intoxication or narcosis, in special positions. The modus of restitution by neighboring cortex, by symmetrical cortex portions (as in aphasia?), and by the central and peripheral levels or intermediate levels (as in the subsidiary automatism of the infracortical centers in Goltz's decerebrated dog) opens interesting prob. lems. The demonstration of vicarious hypertrophy easily demonstrable in the pyramid of young subjects with infantile hemiplegia and the possibility of changes in form and number of cells offer a new and interesting field of observation.

The modified nervous adjustment really marks a new brain-type. Physiologically and psychologically we meet even normally with excessive compensation, as when irritability covers up emotion; and even more plainly in the timidity of the nervous, the laughter of the depressed hysterical. The compensation of psychical defect due to brain-disease is especially worth studying, and Anton points to an interesting divorce of the mere finding of words and the finding of the meaning, which, with Leibnitz, he calls psittacism or parrot-language. A patient of his observation, in whom an abscess of the parietal lobe 
had produced paraphasia and complete alexia, recovered slowly after operation, and learned to read again; but he only learned to recognize the words with the first effort and had to read several times before he grasped the sense. Many changes of character are similar phenomena of compensation.

The whole trend of thought is worth bearing in mind and might easily suggest valuable applications.

\section{A. M.}

\section{REACTION-TIME IN INSANITY.}

The Time of some Mental Processes in the Retardation and Excitement of Insanity. Shepherd Ivory Franz. Amer. J. of Psychol., 1906, XVII., 38-68.

The patients dealt with in these experiments were afflicted with what Kraepelin terms 'manic-depressive insanity.' Six subjects were used in the research, two normal, two depressed (retarded), and two exhilarated (excited). The following experiments were made :

A. The subjects were asked to tap with a pencil as many times as possible for thirty seconds. The results obtained from the excited subjects did not differ greatly at first from those of the normal subjects. The former, however, did not show much practice effect. The retarded patients were much slower, but they improved with practice.

B. The time of reaction to sound stimulus. The averages for the excited patients as compared with the normal shows a slight slowing up of reaction time.

C. Choice reaction time. The excited patients do not show increased rapidity, although they are supposed to have rapid association processes. On the whole, retardation does not necessarily seem to be a decrease in the speed with which a movement is instituted.

D. The average time of reading a word. As practice continued, the normal and the depressed subjects improved, but the excited patients did not.

E. The time taken to mark 100 e's among 850 letters. The excited patients are not as rapid as the normal subjects.

F. The time required to add 20 problems, each consisting of two five-digit figures, placed one above the other. In the order of rapidity the subjects stand at the end of the first week as follows : normal, excited, depressed. One of the excited cases had kept books and stood at the head of the list. Practice is most marked in the case of one of the depressed cases. He improved 60 per cent., while the improvement in the other subjects was not more than 25 per cent. 